Supplementary data

\title{
Highly Effective Production of 5-Hydroxymethylfurfural from Fructose with a Slow-Release Effect of Proton of a Heterogeneous Catalyst
}

\author{
Xiangbo Song, ${ }^{\dagger, \dagger, \S}$ Yuhe Liao, ${ }^{\dagger}$ Yuting Zhu, ${ }^{\dagger, \S}$ Pengyao Sun, ${ }^{\dagger, \S}$ Lungang Chen, ${ }^{\dagger}$ \\ Longlong Ma, ${ }^{\dagger}$ Hongwei Yang, ${ }^{\uparrow, *}$ and Chenguang Wang ${ }^{\dagger}, *$
}

$\uparrow$ CAS Key Laboratory of Renewable Energy, Guangdong Provincial Key Laboratory of New and Renewable Energy Research and Development, Guangzhou Institute of Energy Conversion, Chinese Academy of Sciences, Guangzhou 510640, China.

$\ddagger$ School of Physical and Electronic Sciences, Chuxiong Normal University, Chuxiong 675099, P. R. China.

$\S$ University of Chinese Academy of Sciences, Beijing 100049, P. R. China.

II Energy Research Institute, Academy of Macroeconomics, National Development and Reform Commission, Beijing 100038, P. R. China.

* Corresponding author: Chenguang Wang; Hongwei Yang

E-mail: wangcg@ms.giec.ac.cn; _hyang@eri.org.cn

Tel: +86 $02037029721 ;+861063908180$ 


\section{Color change of the used Amberlyst-15}

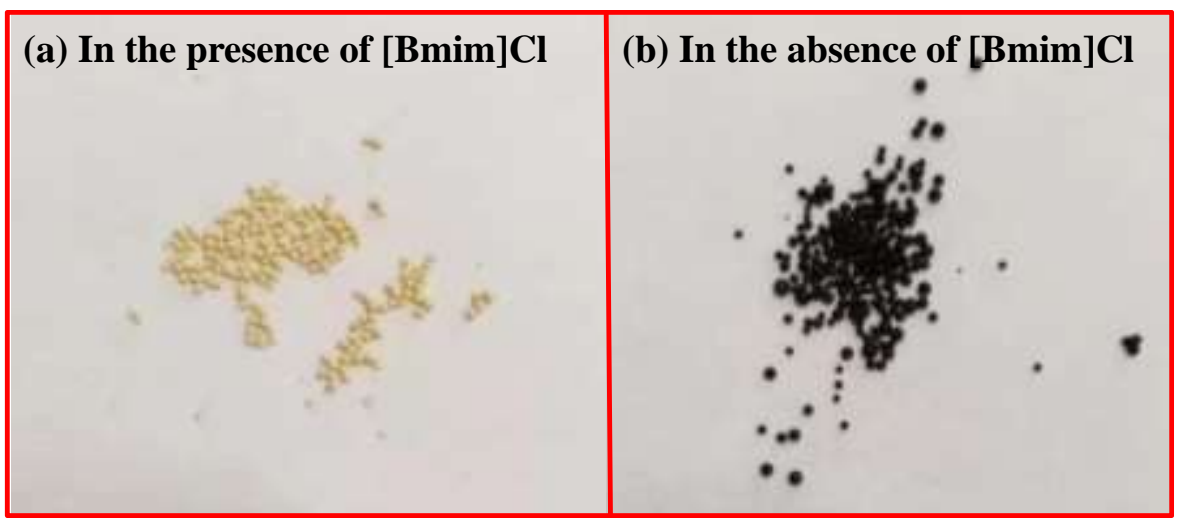

Figure S1. The comparison of the spent Amberlyst-15 in the presence and absence of $[\mathrm{Bmim}] \mathrm{Cl}$.

\section{Color change of reaction solution}

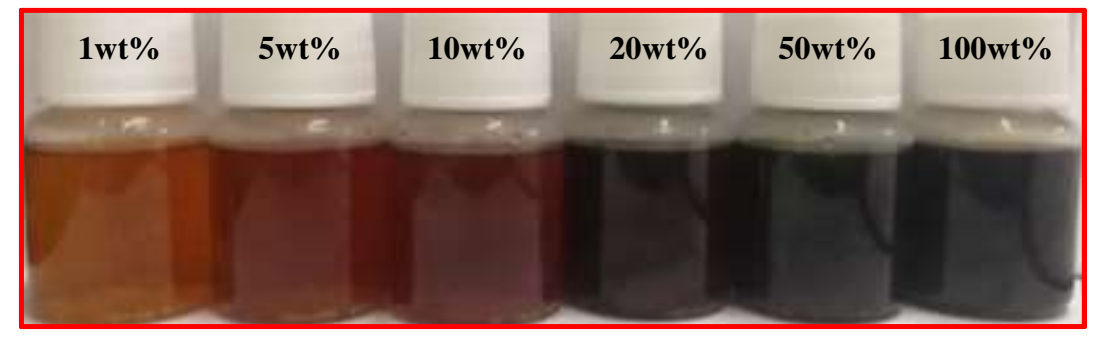

Figure S2. The change in color of reaction solution with different Amberlyst-15 loadings.

pH value of solution over several Amberlyst-15 loadings 


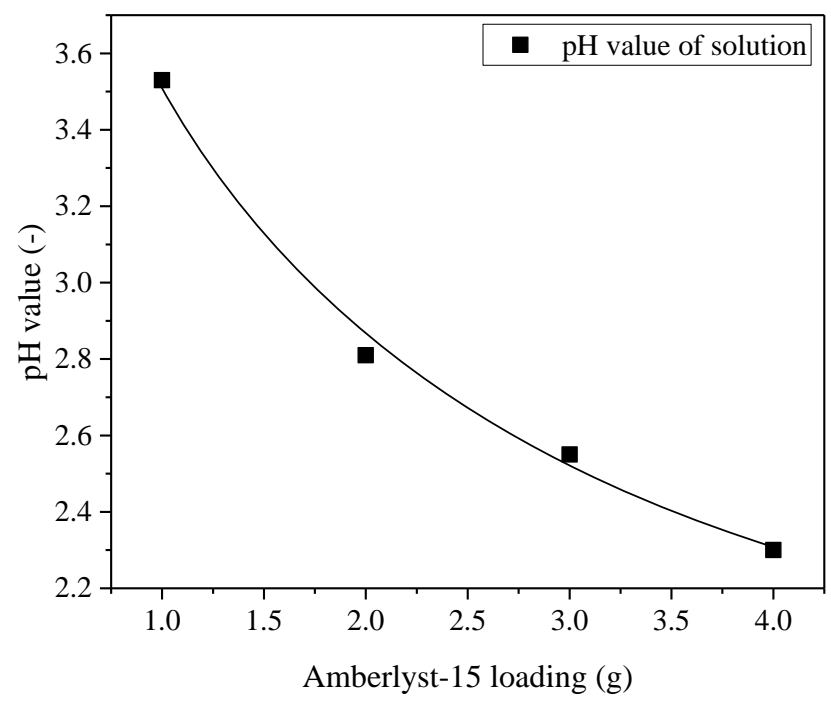

Figure S3. $\mathrm{pH}$ value of solution over different amount of Amberlyst-15 in the presence $[\mathrm{Bmim}] \mathrm{Cl}$.

\section{TG analysis of IL-treated sample}
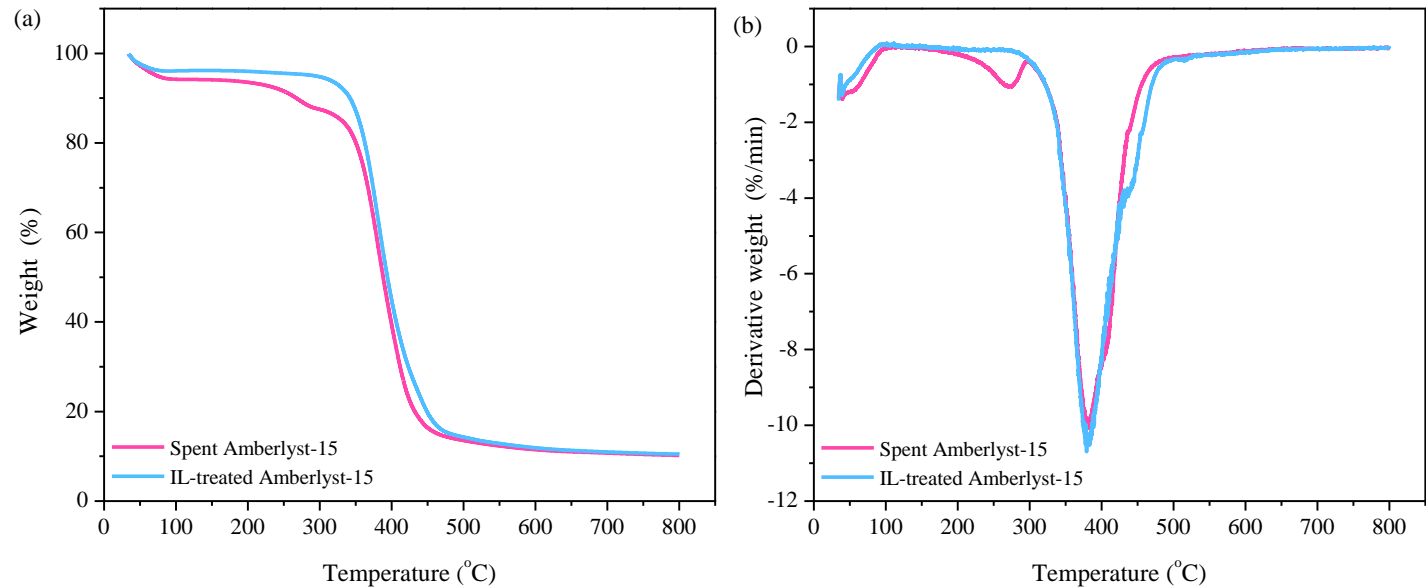

Figure S4. (a) TG and (b) DTG curves of the spent and IL-treated Amberlyst-15 catalyst.

Acid amount of Amberlyst-15 catalyst

Table S1. Amount of acid sites on Amberlyst-15 catalyst 


\begin{tabular}{lll}
\hline Entry & Catalyst & $\begin{array}{l}\text { Amount of acid sites } \\
(\mathrm{mmol} / \mathrm{g})\end{array}$ \\
\hline 1 & Fresh Amberlyst-15 & 2.94 \\
2 & IL-treated Amberlyst-15 & 2.21 \\
\hline
\end{tabular}

${ }^{\text {a }}$ Determined by pyridine adsorbed FT-IR.

\section{Testing process for $\mathrm{H}^{+}$concentration in the absence and presence of $[\mathrm{Bmim}] \mathrm{Cl}$}

At room temperature, $15 \mathrm{wt} \%$ of $[\mathrm{Bmim}] \mathrm{Cl}$ (if present) and $20 \mathrm{~mL}$ deionized water were added to a thick-walled glass container, meanwhile the electrode of $\mathrm{pH}$ meter was fixed in the container and kept the electrode probe in effective contact with solution. Then, $0.1 \mathrm{~g}$ of Amberlyst-15 resin was added to the above solution along with testing the $\mathrm{pH}$ value of solution at this moment, which was marked as 0 min. At the same time, the agitator was started and the $\mathrm{pH}$ values of solution at different time nodes were tested by $\mathrm{pH}$ meter (Figure S5). The $\mathrm{H}^{+}$concentration at different cases and time points is calculated according to the formula $\mathrm{pH}=-\lg \left[\mathrm{H}^{+}\right]$.

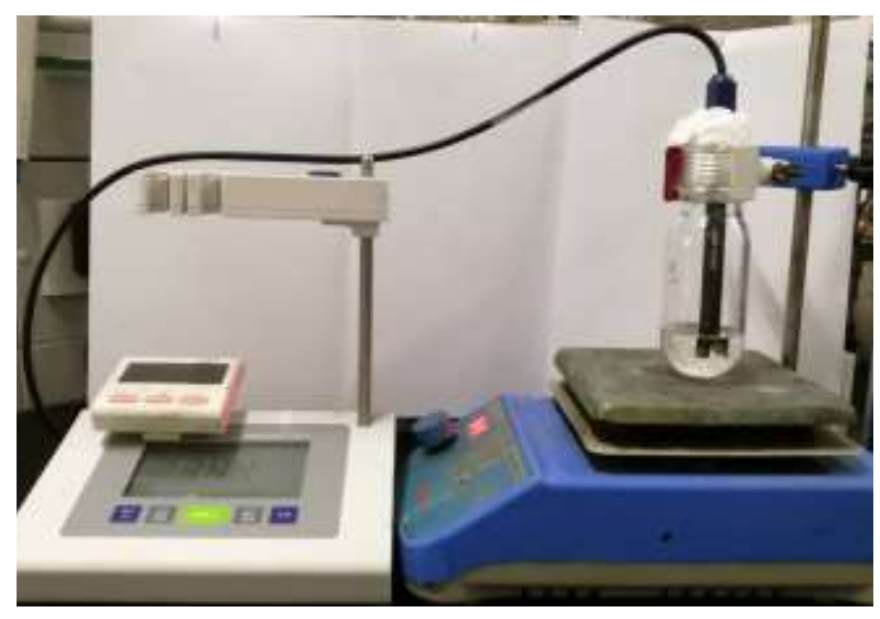

Figure S5. Testing equipment of $\mathrm{H}^{+}$release from Amberlyst- 15 . 


\section{pH test in three solutions}

Experimental process: $0.1 \mathrm{~g}$ of Amberlyst-15 (if present) and $15 \mathrm{wt} \%$ of $[\mathrm{Bmim}] \mathrm{Cl}$ (if present) were added to $20 \mathrm{~mL}$ deionized water, respectively. The solution containing single $[\mathrm{Bmim}] \mathrm{Cl}$ was denoted as solution $\mathrm{A}$. The solution containing single Amberlyst-15 was denoted as solution $\mathrm{B}$. The solution containing both [Bmim] $\mathrm{Cl}$ and Amberlyst-15 was denoted as solution $\mathrm{C}$. The $\mathrm{pH}$ value of the above solution was first tested by $\mathrm{pH}$ meter. Then, at room temperature (ca. $30{ }^{\circ} \mathrm{C}$ ), the prepared sodium hydroxide solution $(0.01 \mathrm{M})$ was slowly dropped into the above solutions $(\mathrm{A}, \mathrm{B}$ and C), and the titration stopped until the $\mathrm{pH}$ of the solution reached neutral (about 7.00). At the same time, the change in $\mathrm{pH}$ value of the above three solutions was recorded, and the results were shown in Figure S6.

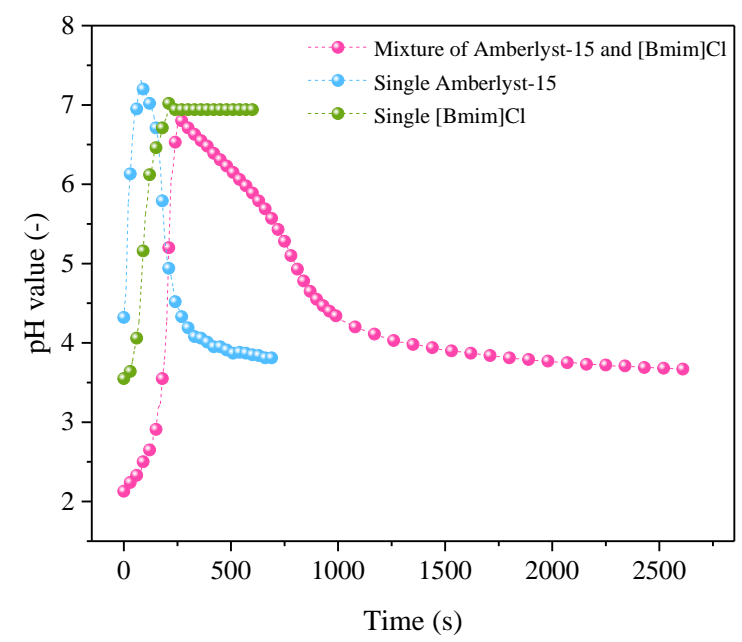

Figure S6. Change in $\mathrm{pH}$ of the solution with adding single $[\mathrm{Bmim}] \mathrm{Cl}$, single Amberlyst-15 and mixture of Amberlyst-15 and [Bmim]Cl. 


\section{Corrosiveness testing of system with Amberlyst-15 and $\mathrm{HCl}$ as catalyst}

For the case using heterogeneous Ambelyst-15 as catalyst in the presence of $[\mathrm{Bmim}] \mathrm{Cl}$, the mixture of Amberlyst-15 (0.5 g), [Bmim]Cl (15wt\%), iron nail $(0.864$ $\mathrm{g})$ and deionized water $(20 \mathrm{~mL})$ were added to round-bottom flask. The above mixture was then heated at $100{ }^{\circ} \mathrm{C}$ for $24 \mathrm{~h}$ and $72 \mathrm{~h}$, respectively, with reflux and agitation. After that, the remained iron nail and solid Amberlyst-15 were removed and the remained solution was digested with $\mathrm{HNO}_{3}$ for ICP analysis. For the case directly using homogeneous $\mathrm{HCl}$ as catalyst, firstly, a certain amount of $\mathrm{HCl}$ was used to adjust the $\mathrm{pH}$ value of solution $(\mathrm{pH}=1.59)$ to be consistent with the above Amberlyst-15 and $[\mathrm{Bmim}] \mathrm{Cl}$ mixture system $(\mathrm{pH}=1.60)$. Then, the iron nail $(0.859 \mathrm{~g})$ along with the above solution was added to round-bottom flask. Finally, the above mixture was heated at $100{ }^{\circ} \mathrm{C}$ for $24 \mathrm{~h}$ and $72 \mathrm{~h}$, respectively, with reflux and agitation. Subsequently, the remained iron nail was removed and the remained solution was digested with $\mathrm{HNO}_{3}$ for ICP analysis. Results are depicted in Figure S7.
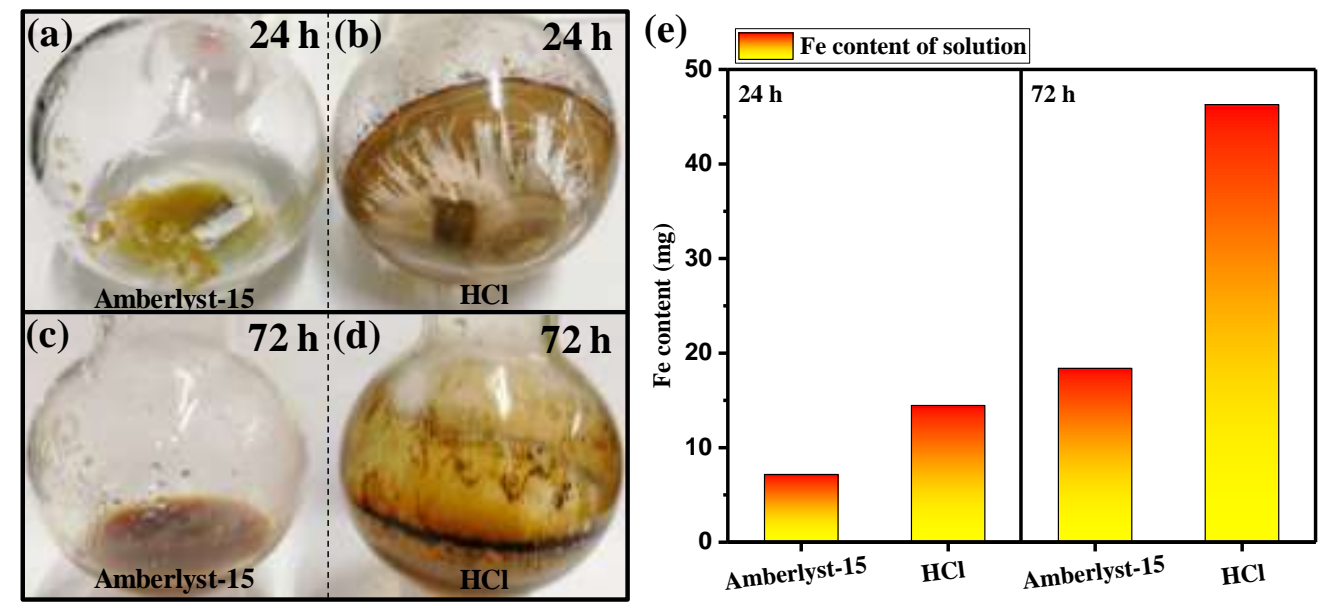

Figure S7. Comparison of corrosiveness of system (a, b, c and d) and Fe content of 
solution (e) under catalysis of Amberlyst-15 and $\mathrm{HCl}$.

Figure S7 gives the comparison of corrosiveness under catalysis of Amberlyst-15 and $\mathrm{HCl}$. Figures S7 a and c represent reaction system with Amberlyst-15 as catalyst in the present of $[\mathrm{Bmim}] \mathrm{Cl}$ for $24 \mathrm{~h}$ and $72 \mathrm{~h}$, respectively. Figures $\mathrm{S} 7 \mathrm{~b}$ and $\mathrm{d}$ represent reaction system with $\mathrm{HCl}$ as catalyst for $24 \mathrm{~h}$ and $72 \mathrm{~h}$, respectively. It can be seen that the corrosiveness of system with Amberlyst-15 as catalyst in the presence of $[\mathrm{Bmim}] \mathrm{Cl}$ was obviously weaker than the case that directly used $\mathrm{HCl}$ as catalyst (Figure S7 a-d). Besides, according to the ICP analysis, the Fe content in solution with Amberlyst-15 catalyst was lower than the case with $\mathrm{HCl}$ catalyst (Figure S7e). These results indicate that the system with Amberlyst-15 as catalyst and $[\mathrm{Bmim}] \mathrm{Cl}$ as additive exhibited a less corrosiveness than the homogeneous catalysis process that directly used mineral acid $\mathrm{HCl}$ as catalyst.

\section{Effect of [Bmim]Cl loading on the HMF yield and solution pH}

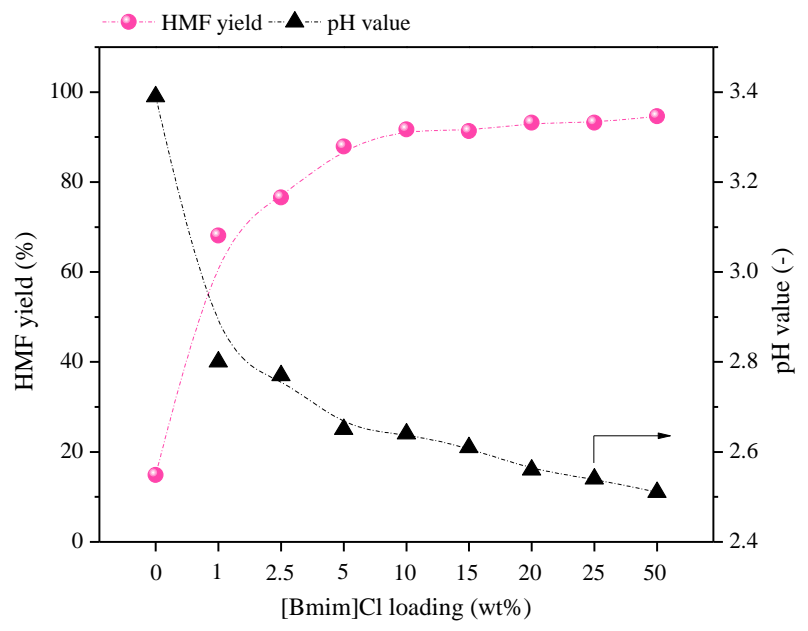


Figure S8. HMF yield and $\mathrm{pH}$ value of solution as a function of [Bmim]Cl loading.

\section{Effect of reaction temperature and time}

Reaction temperature and time greatly affect the catalytic performance of catalyst for carbohydrate conversion ${ }^{1}$. Hence, the effect of reaction temperature and time on the fructose conversion over Amberlyst-15 catalyst was systematically investigated in the presence of $[\mathrm{Bmin}] \mathrm{Cl}$ (Figure S9). Results show that under the low reaction temperature of $80{ }^{\circ} \mathrm{C}$, a relatively low fructose conversion of $84.8 \%$ was observed within $10 \mathrm{~min}$, while the higher fructose conversion (e.g., 94.1\%, 97.2\% and 98.0\%) could be achieved with elevating reaction temperature to $90{ }^{\circ} \mathrm{C}, 100^{\circ} \mathrm{C}$ and $110^{\circ} \mathrm{C}$, respectively (Figure S9a). This suggests that high temperature was conducive to improving the catalytic performance of Amberlyst-15 for fructose conversion. Meanwhile, the corresponding yield of HMF exhibited a similar trend that rapidly increased with increasing reaction temperature, while it slightly decreased with extending the reaction time at high temperature conditions (Figure S9b). In addition, the high temperature was more favorable for the rapid formation of HMF. When reaction was carried out at low temperature of $80{ }^{\circ} \mathrm{C}$, a relative low HMF yield of $75.5 \%$ was obtained within the first $10 \mathrm{~min}$. Expectedly, as the reaction was operated at high temperature of $110^{\circ} \mathrm{C}$, a relatively higher $\mathrm{HMF}$ yield of $85.3 \%$ could be achieved in $10 \mathrm{~min}$. Thereafter, it rapidly increased to the maximum yield of $93.8 \%$ within $60 \mathrm{~min}$. However, further prolonging the reaction time to $180 \mathrm{~min}$, HMF yield gradually decreased to $86.3 \%$. This was strongly attributed to the instability of HMF to form 
humins species through side reactions like condensation of HMF under high temperature ${ }^{2,3}$. The above results indicate that although the high temperature could improve the catalytic performance of Amberlyst-15 for the rapid dehydration of fructose to HMF, it also accelerated the occurrence of side reactions involving HMF.
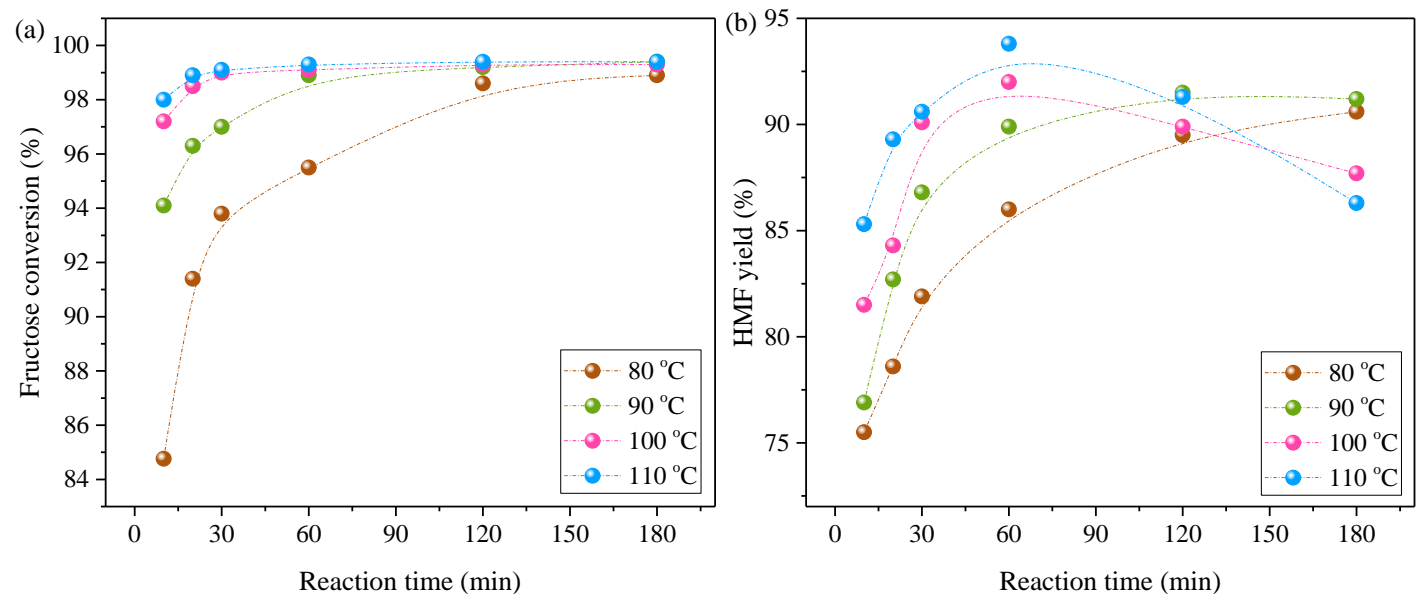

Figure S9. Effect of reaction temperature and time on the fructose conversion (a) and $\mathrm{HMF}$ yield (b) in the presence of $[\mathrm{Bmim}] \mathrm{Cl}$. Reaction conditions: $0.2 \mathrm{~g}$ of fructose, $0.02 \mathrm{~g}$ of Amberlyst- 15 catalyst, $4 \mathrm{~mL}$ THF, $15 \mathrm{wt} \%$ of $[\mathrm{Bmim}] \mathrm{Cl}$.

\section{Fructose dehydration in various solvents}

The reaction solvent is an important factor affecting the conversion of carbohydrates to HMF. Fructose conversion to HMF over Amberlyst-15 catalyst in the presence of $[\mathrm{Bmim}] \mathrm{Cl}$ additive was further investigated in various organic solvents (Figure S10). The fructose conversion in all tested organic solvents (including GVL, GBL, 1,4-dioxane, DMSO, DMF and THF) was found essentially the same and almost all could achieve a complete conversion under the operating temperature of 
$100{ }^{\circ} \mathrm{C}$ for $1.0 \mathrm{~h}$. Meanwhile, there was a slight difference in the corresponding yield of HMF. When GVL, GBL, 1,4-dioxane, DMSO and THF were used as the reaction medium, all the obtained yields of HMF could be up to $90 \%$. Nevertheless, with using DMF as solvent, a slightly low yield of HMF of $88.2 \%$ was attained. The reason may be that DMF is a polar aprotic solvent containing amino groups, partial acidic sites could be neutralized by the amino groups during the fructose dehydration process ${ }^{4}$, leading to a slight decrease in HMF yield. The results above suggest that the addition of a small ratio of $[\mathrm{Bmim}] \mathrm{Cl}$ additive into organic solvent was an efficient strategy for promoting fructose dehydration towards HMF. Whereas, when it comes to the subsequent separation and purification of HMF from reaction mixture, the solvent with high boiling point (e.g., DMF, GVL, GBL and DMSO) are thus less to use as the reaction medium, owing to it potentially causing higher energy consumption. The low boiling point THF $\left(66^{\circ} \mathrm{C}\right)$ solvent, being derived from biomass feedstock ${ }^{5}$, is a good candidate in consideration of the energy saving in the subsequent separation of HMF.

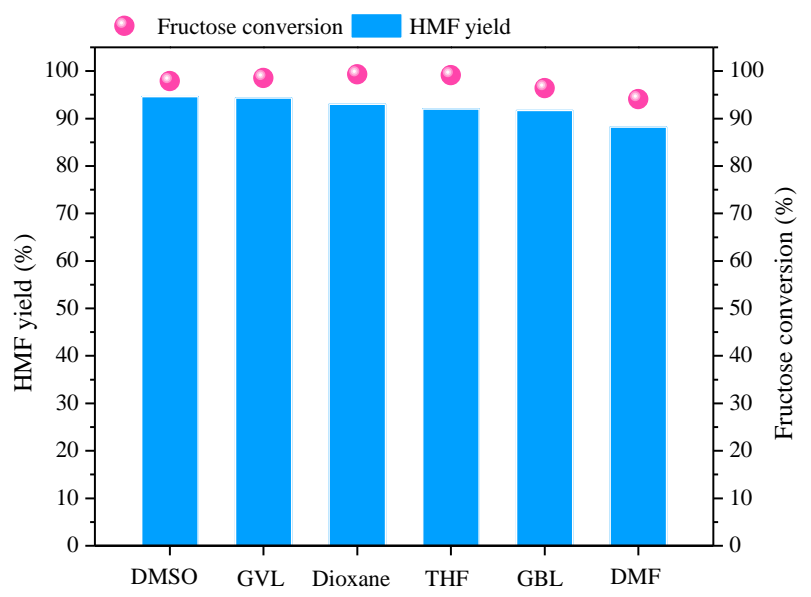

Figure S10. Fructose conversion into HMF in various organic solvents in the 
presence of [Bmim]Cl. Reaction conditions: $0.2 \mathrm{~g}$ of fructose, $0.02 \mathrm{~g}$ of Amberlyst-15, $4 \mathrm{~mL}$ solvent, $15 \mathrm{wt} \%$ of $[\mathrm{Bmim}] \mathrm{Cl}, 100{ }^{\circ} \mathrm{C}, 1.0 \mathrm{~h}$.

\section{Conversion of various carbohydrates}

Owing to the beneficial effect of slow-release of $\mathrm{H}^{+}$species for dehydration of fructose to $\mathrm{HMF}$, the slow-release effect involving Amberlyst-15 and [Bmim]Cl was thus further employed to achieve the conversion of various complex carbohydrates, including monosaccharides (e.g., glucose and xylose), disaccharides (sucrose and cellobiose) and polysaccharides (e.g., inulin and starch), under similar reaction conditions (Figure S11). As seen in Figure S11, a satisfying HMF yield of $69.2 \%$ could be obtained from conversion of inulin, a polysaccharide mainly consisted of fructose unit, in line with the results from fructose. Similarly, conversion of sucrose, a disaccharide consisted of repeat unit of one fructose and one glucose, gave a considerable yield of $63.2 \%$ towards HMF. With glucose, cellubiose (a glucose dimer) and starch (a glucose polymer) as the substrate, moderate HMF yields of $41.3 \%, 40.2 \%$ and $32.6 \%$ were achieved, respectively. The main component for glucose, cellubiose and starch was glucose monomer. Since the process of glucose conversion to HMF was more complex than fructose, ${ }^{6}$ thus leading to a low HMF yield. Additionally, dehydration of xylose, a pentose that occupied the main components of hemicellulose, was conducted in the catalytic system, giving a good furfural yield of $51.9 \%$ at low temperature $\left(140^{\circ} \mathrm{C}\right)$ and short time $(30 \mathrm{~min})$. All these above results demonstrate that 
the slow-release effect involving Amberlyst-15 and [Bmim]Cl could be also employed in the complex carbohydrate conversion with satisfactory yields.

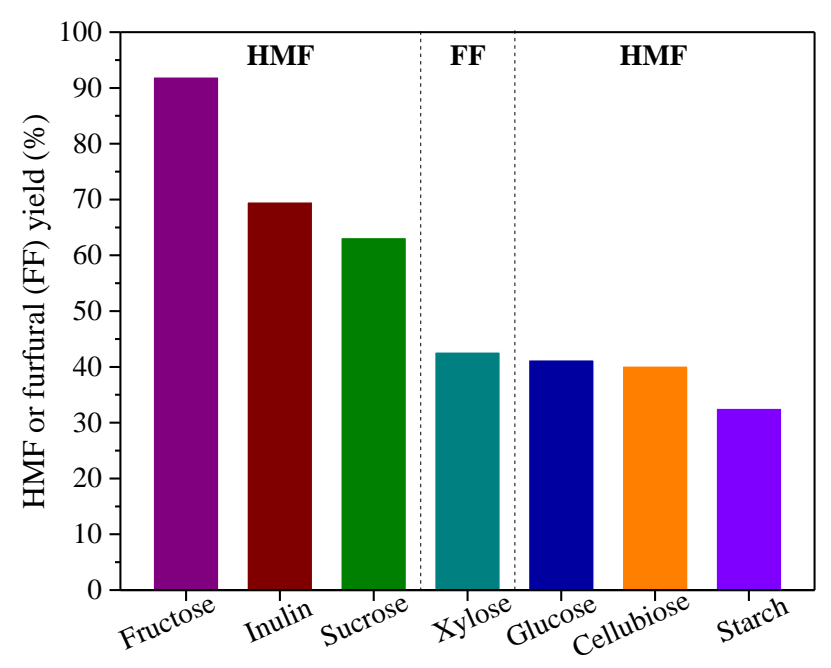

Figure S11. Conversion of various carbohydrates to HMF or furfural. Reaction conditions: $0.2 \mathrm{~g}$ of substrate, $0.02 \mathrm{~g}$ of Amberlyst- $15,15 \mathrm{wt} \%$ of [Bmim]Cl, $4 \mathrm{~mL} \mathrm{THF}$, $100{ }^{\circ} \mathrm{C}, 60 \mathrm{~min}$.

\section{Effect of substrate concentration}

The tolerance of high substrate concentration is generally employed to evaluate the efficiency of catalytic system in terms of process economy. Here, the slow-release effect of $\mathrm{H}^{+}$of Amberlyst-15 induced by [Bmim]Cl additive was further tested at high concentration condition of substrate (Table S3). As shown in Table S3, when a low $2.5 \mathrm{wt} \%$ of fructose concentration was employed, HMF in $85.8 \%$ yield along with $98.7 \%$ of fructose conversion was attained under mild conditions of $100{ }^{\circ} \mathrm{C}$ within $60 \mathrm{~min}$. The HMF yield could reach to $92.0 \%$ with $99.1 \%$ of fructose conversion at the 
fructose concentration of $5.0 \mathrm{wt} \%$. Whereas, further increasing the fructose concentration to $10 \mathrm{wt} \%$, fructose conversion could reach up to $98.8 \%$ while the HMF yield slightly decreased to $84.2 \%$. This was mainly ascribed to that high HMF concentration in system increased its self-condensation probability, resulting in HMF being consumed through side reactions. Additionally, with the fructose concentration being up to $20 \mathrm{wt} \%$, the fructose conversion could still reach up to $95.8 \%$ meanwhile achieved $64 \%$ HMF yield, demonstrating that this reaction system maintained a good catalytic activity owing to the slow-release effect of $\mathrm{H}^{+}$induced by $[\mathrm{Bmim}] \mathrm{Cl}$. Thus, the high fructose concentration could be effectively converted to HMF even at low catalyst loading.

Table S2. HMF synthesis from various fructose concentrations ${ }^{\text {a }}$

\begin{tabular}{|c|c|c|c|c|}
\hline \multirow{2}{*}{ Entry } & \multirow{2}{*}{$\begin{array}{l}\text { Fructose } \\
\text { concentration } \\
(\mathrm{wt} \%)\end{array}$} & \multicolumn{2}{|c|}{ Mole yield (\%) } & \multirow{2}{*}{$\begin{array}{l}\text { Fructose } \\
\text { conversion } \\
(\%)\end{array}$} \\
\hline & & LA & HMF & \\
\hline 1 & 2.5 & - & 85.8 & 98.7 \\
\hline 2 & 5.0 & - & 92.0 & 99.1 \\
\hline 3 & 7.5 & - & 90.6 & 99.4 \\
\hline 4 & 10 & - & 84.2 & 98.8 \\
\hline 5 & 20 & - & 64.0 & 95.8 \\
\hline
\end{tabular}

${ }^{\mathrm{a}}$ Reaction conditions: fructose as substrate, $0.02 \mathrm{~g}$ of Amberlyst- 15 catalyst, $4 \mathrm{~mL}$ THF, $15 \mathrm{wt} \%$ of $[\mathrm{Bmim}] \mathrm{Cl}, 100{ }^{\circ} \mathrm{C}, 1.0 \mathrm{~h}$. The fructose concentration is relative to the volume of THF solvent (w/v).

pH of solution in the presence of various ionic liquids additives 


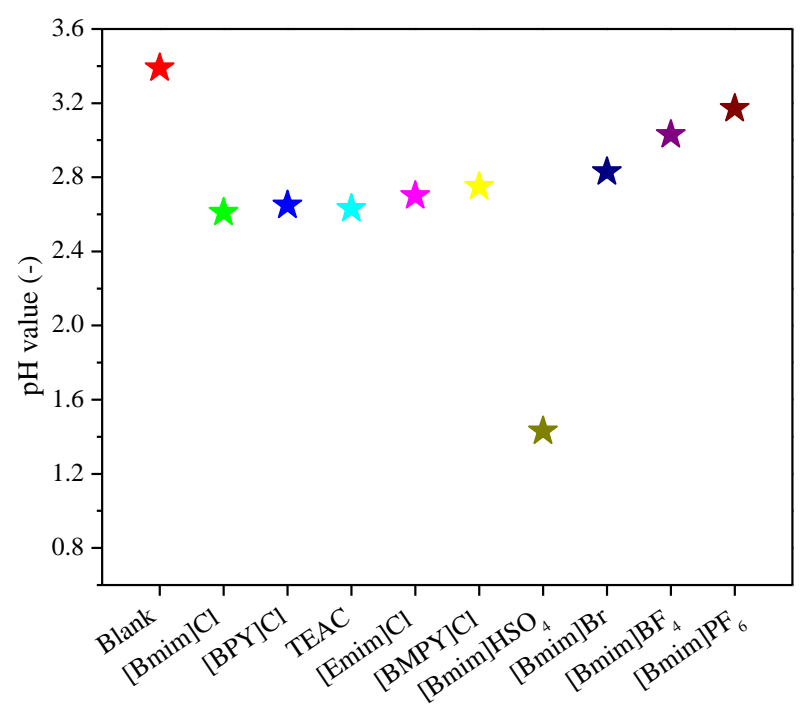

Figure S12. $\mathrm{pH}$ value of solution in the presence of various ionic liquids additive.

\section{References}

(1) Cao, J.; Ma, M.; Liu, J.; Yang, Y.; Liu, H.; Xu, X.; Huang, J.; Yue, H.; Tian, G.;

Feng, S., Highly effective transformation of carbohydrates to 5-Hydroxymethylfurfural with Al-montmorillonite as catalyst. Appl. Catal. A 2019, 571, 96-101.

(2) Jung, D.; Körner, P.; Kruse, A., Kinetic study on the impact of acidity and acid concentration on the formation of 5-hydroxymethylfurfural (HMF), humins, and levulinic acid in the hydrothermal conversion of fructose. Biomass Convers. Biorefin. 2019, 1-16.

(3) Körner, P.; Jung, D.; Kruse, A., Influence of the pH Value on the Hydrothermal Degradation of Fructose. ChemistryOpen 2019, 8, (8), 1121-1132. 
(4) Sampath, G.; Kannan, S., Fructose dehydration to 5-hydroxymethylfurfural: Remarkable solvent influence on recyclability of Amberlyst-15 catalyst and regeneration studies. Catal. Commun. 2013, 37, 41-44.

(5) Morales-Leal, F. J.; Rivera de la Rosa, J.; Lucio-Ortiz, C. J.; De Haro-Del Rio, D. A.; Solis Maldonado, C.; Wi, S.; Casabianca, L. B.; Garcia, C. D., Dehydration of fructose over thiol- and sulfonic- modified alumina in a continuous reactor for 5HMF production: Study of catalyst stability by NMR. Appl. Catal. B 2019, 244, 250-261.

(6) Li, X.; Xia, Q.; Nguyen, V. C.; Peng, K.; Liu, X.; Essayem, N.; Wang, Y., High yield production of HMF from carbohydrates over silica-alumina composite catalysts. Catal. Sci. Technol. 2016, 6, (20), 7586-7596. 